Awe and Epistemology in a Science Museum

C. Aaron Price ${ }^{1}$, Kimberly A. Quinn ${ }^{2}$, Jana Greenslit ${ }^{1}$, Lauren Applebaum ${ }^{1}$, Sheila KroghJespersen $^{2,3}$, William L. D. Krenzer ${ }^{2,4}$, Roberta Ibtasar ${ }^{1}$

${ }^{1}$ Museum of Science and Industry, Chicago

${ }^{2}$ DePaul University

${ }^{3}$ Northwestern University, Feinberg School of Medicine

${ }^{4}$ Duke University

Corresponding Authors:

C. Aaron Price, Museum of Science and Industry, 5700 S. Lake Shore Dr., Chicago IL 60605; aaron.price@msichicago.org

Kimberly A. Quinn, Department of Psychology, DePaul University, 2219 N. Kenmore Ave., Chicago IL 60614; k.quinn@depaul.edu

Acknowledgement:

We acknowledge the support of the following: A. Anderson, K. Greven, N. Harris, A.

Mroczkowski, C. Nguyen, G. Segovia, and G. Vaishampayan. 


\begin{abstract}
Museums are located at the intersection of awe and learning: When guests arrive, they are expecting to be amazed, inspired, and educated. This is particularly true in science museums, and researchers have pointed to awe as an epistemic emotion that can promote science learning. We present two studies of awe in a science museum. The first study $(n=293)$ examined how aweconceptualized as a multifaceted construct associated with positive feelings of liberation/connection, negative feelings of oppression/isolation, chills, and diminished-self perceptions - differed across museum locations and in relation to prior knowledge. The second study $(\mathrm{n}=708)$ expanded the investigation to also examine the relationship between awe and critical thinking. Across both studies, we found that, relative to baseline spaces, vast, beautiful spaces elicited positive awe-related emotions (amazement, curiosity) and stronger awe correlates (chills, diminished-self perceptions); vast, threatening spaces also elicited stronger amazement, chills, and diminished-self perceptions - but also stronger oppression/isolation. In both studies, pre-visit knowledge was associated with awe experiences during the visit. In Study 2, we also found evidence for relationships between awe and skepticism and aesthetic thought, two aspects of critical thinking: Positive aspects of awe (liberation/connection, curiosity) were associated with more skepticism, and negative aspects of awe (oppression/isolation, disorientation) with less skepticism. In terms of aesthetic thinking, diminished-self perceptions were associated being able describe observed roles and actions, and chills were associated with being able to describe personal opinions. These results support the assertion that awe can be used to encourage engagement and learning in informal science settings.
\end{abstract}

Keywords: awe, critical thinking, science education, museums, informal learning 
Awe and Epistemology in a Science Museum

As a feeling of reverential respect mixed with fear or wonder (Oxford English Dictionary, n.d.), awe has been proposed as a catalyst for science learning (Valdesolo, Shtulman, \& Baron, 2017). Indeed, in one of his last public talks, which he titled Wonder and Skepticism, Carl Sagan described the moment when, as a child, he considered the distance to the stars: "The dazzling idea of a universe vast beyond imagining swept over me. It has stayed with me ever since. I sensed awe" (Sagan, 1995). Ann Druyan, his writing partner and an independently established expert in science education, believes that awe and wonder are key to skepticism and belief in science (Grothe, 2006).

A natural and accessible place to experience awe is in museums, which are often designed explicitly to induce awe and similar emotions in their guests. For example, museum architects often use the compression and expansion effect to induce awe by forcing guests to walk down narrow corridors before being presented into a large, immersive open space. Guests come to museums "with expectations to see wondrous things that they cannot see in their everyday lives" (Smith, 2014) and they come ready to learn and are generally in a receptive state of mind. This combination of feeling awe while also being open to learning is an ideal environment for education. The aim of this research project was to explore whether designed museum spaces differ in their capacity to evoke awe and in the nature of awe that they do evoke, and to test the hypothesis that the extent to which museum spaces evoke awe influences guests' skeptical and aesthetic thinking.

\section{Awe and Science Learning}

In the most comprehensive theoretical analysis of awe to date, Keltner and Haidt (2003) identified two key features of stimuli that are likely to elicit the emotion of awe: perceived vastness and need for accommodation. Vast stimuli challenge the individual's understanding of 
the world — not only by virtue of sheer physical size (e.g., the Grand Canyon), but also in terms of sensory detail (e.g., a complex work of art), social or historical importance (e.g., an event that affects thousands of people), explanatory power and conceptual breadth (e.g., a complex theory), or even just volume of unexpected information (Shiota, Thrash, Danvers, \& Dombrowski, 2014). These challenges to understanding require cognitive accommodation - updating our worldview to establish meaning - and motivate us to learn. Awe is the emotion we experience in response to our recognition that something is so great that it defies what we can currently understand — that feeling of reverence, tinged with wonder and/or fear.

Stated differently, awe is an epistemic emotion (Silvia, 2008; Valdesolo, Park, \& Gottlieb, 2016), evoked by knowledge tasks and knowledge-generating activities (Trevors, Muis, Pekrun, Sinatra, \& Winne, 2016). Epistemic emotions and related affect can instigate and stabilize learning in science (Jaber \& Hammer, 2016a; Jaber \& Hammer, 2016b), and include not only awe, but also emotions such as interest, curiosity, confusion, and surprise. They often operate in tandem. Awe, for example, might be accompanied by confusion and surprise to the extent that events that evoke awe are those that cannot be comprehended fully within preexisting knowledge schemas. Moreover, these events can create uncertainty that often leads to curiosity and interest. Such feelings of uncertainty have been identified as particularly important for education around controversial scientific topics, such as evolution (Ha, Haury, \& Nehm, 2012) and climate change (Lombardi \& Sinatra, 2012).

Awe's status as an epistemic emotion has been supported by several independent lines of research. Most recently, awe has been shown to promote awareness of knowledge gaps and science interest (McPhetres, 2019): Participants who were induced to experience nature-related awe via video clips or virtual reality, relative to baseline participants, were more likely to 
endorse statements such as "I ask myself if I really understand how the natural world works," to report that they found science magazines interesting, and to choose a ticket to a science museum over an art museum.

However, it is not merely the case that awe provokes awareness and interest. Empirical evidence also suggests that awe has implications for the kinds of thinking that are conducive to science learning. Danvers and Shiota (2017), for example, experimentally induced awe and compared it to either a general positive emotion state or a neutral emotion state. Participants induced to feel awe, relative to other participants, relied less on preexisting knowledge, inserting fewer "false" but schema-consistent details into memory recollections. These findings suggest that awe helps individuals limit their use of the schema-driven expectations that they would normally use to understand the world. In the context of science learning, awe may support individuals' ability to challenge their naive beliefs (e.g., about how gravity operates, the causes of climate change; cf. Valdesolo et al., 2017).

There is also evidence that awe induces "better" thinking. For example, awe has been shown to promote ethical decision making (Piff, Dietze, Feinberg, Stancato, \& Keltner, 2015). Some empirical evidence also supports the role of awe in promoting critical thinking. In one study, participants who were cued to remember memories of awe were less likely than participants in a control condition to be persuaded by weak arguments subsequently presented to them, that is they were more critical in their thought (Griskevicius, Shiota, \& Neufeld, 2010). Other research has demonstrated that the self-reported tendency to feel awe is associated with less discomfort with uncertainty (Shiota et al., 2007) and greater understanding of more nuanced aspects of science and being more resistant to weak scientific arguments (Gottlieb, Keltner \& Lombrozo, 2018). Awe, in making individuals aware of the limitations of their knowledge and 
stimulating their interest in gaining more knowledge, is associated with more careful evaluation of the evidentiary value of information.

\section{Theoretical Framework}

Vygotsky considered emotion as an inseparable part of the basis of cognition and thought (Vygotsky, 1926, 1997; Mahn \& John-Steiner, 2002; Roth \& Lee, 2007). Emotions are considered an important aspect of conceptual change in science learning (Zembylas, 2005; Treagust \& Duit, 2008). Emotions have also been shown to enhance science achievement by encouraging cognitive engagement (Sinatra, Broughton \& Lombardi, 2014; RappoltSchlictmann, Evans, Reich \& Cahill, 2017), motivation (Pintrinch, 2003; Coleman, 2014) and long-term science learning (King, Ritchie, Sandhu \& Henderson, 2015) perhaps through causing physiological and hormonal responses that help encode memories (Cahill, 2000). But emotions are complex and need to be studied in a manner integrated with the learning context in which they are experienced (Hascher, 2010).

Like others, we propose that awe might be a particularly potent catalyst for learning — and for science learning, in particular (Coleman, 2014; Valdesolo, et al., 2017). Expectancy violations have been shown to stimulate learning in both children and adults (Lorini \& Castelfranchi, 2007; Stahl \& Feigenson, 2015), and awe translates expectancy violations and knowledge gaps into scientific interest (McPhetres, 2019), thus motivating learning. Awe can also lead to questions about whether new or prior knowledge is accurate-driving skepticism, a key component of critical thinking (Lai, 2011). In short, through expectancy violation, knowledge gap awareness, surprise and disequilibration, feelings of awe can prompt a learner to both question prior knowledge schemas and to be more open to (but also critical of) new ideas or information. 
In suggesting that awe enables people to "let go" of their prior knowledge, we are not suggesting that prior knowledge is irrelevant to the awe experience. In fact, prior knowledge is critical to experiencing awe. Awe is assumed to arise when current experience cannot be accommodated within existing knowledge. Individuals experience awe when they are confronted with an unexpected event (unexpected in that it is either entirely novel or highly inconsistent with experience) and when the resulting knowledge gap can only be reduced through cognitive accommodation. To the extent that individuals have strong schemas, they should better able detect knowledge gaps. As such, prior knowledge should promote the experience of awe.

The museum-based link between awe and learning may occur through aesthetic thinking. In addition to creating feelings of awe, museums are a well-known source for teaching and supporting aesthetic thought processes (Lankford, 2002; Smith \& Smith, 2006), which can be a source of growth in critical thinking skills (Housen, 2002, 2007; Hubard, 2011; Kokkos, 2013). Thus, we posit that, in museums, awe is a mediator of various aspects of critical thinking such as the use of prior knowledge, skeptical thinking and aesthetic thought.

\section{Research Context}

Emotions in general have long been linked to cognitive outcomes (Pekrun \& Schutz, 2007; Rienties, \& Rivers, 2014) and their impacts on learning are well studied in academia (Linnenbrink-Garcia \& Pekrun, 2011). However, very few are studying emotions and cognition

outside of the classroom — despite the fact that much of lifelong learning occurs in such informal learning environments and activities (Falk \& Dierking, 2010). Informal learning settings can be an ideal environment for studying emotions in learning due to its flexibility to draw emotions from across the scale from micro to macro (Sinatra, Heddy \& Lombardi, 2015). Most existing 
studies of awe are based on laboratory and/or experimentally induced conditions, usually through the use of video, photographs or recalled memories, which limits the generality of the results.

Museums offer a rare opportunity to measure the impact of naturalistic awe. In epistemic emotion research in general, researchers have noted the differences between emotions induced experimentally or occurring naturally, suggesting they might lead to differing outcomes (Trevors et al., 2016; Makin, 2017). In museums, guests are presented with awe-inspiring stimuli as part of the very design of the experience. This stimuli goes beyond what can be offered in most laboratory environments since it involves the entire physical space, content that comes before and after the experience, and also the social aspects of awe (e.g., feeling awe by seeing something through the eyes of a child). In museums and other informal learning environments, emotions such as arousal and enjoyment have been linked to greater long-term learning in science (Falk \& Gillespie, 2009; Author, , 2015), conservation (Ballantyne, Packer, Hughes \& Dierking, 2007), history (Sakr, Jewitt, \& Price, 2016) and aesthetic contexts (Greene, 2014). Museums are a natural place to study naturalistic awe and test current theories about awe and emotions in learning.

The main context for this study is a large, urban science museum in the United States. Constructed in 1891, the Museum of Science and Industry, Chicago (hereafter, MSI-Chicago) was originally built to house fine art during the 1893 Columbian Exposition and World's Fair. Designed in a Beaux-Arts style, it is situated in a large park surrounded by lakes and grassy fields. The Museum has two public entrances. One is on the surface and behind a grassy knoll. The other is in an underground parking garage. Both entrances lead to a cavernous main hall. Once guests have tickets, they usually leave the main hall and enter via a stairway leading up to a main rotunda. The rotunda is a large, domed area with exhibit galleries on three sides. Designed 
to create an awe-inspiring moment, guests can view a 727 aircraft hanging from a ceiling in one direction, and in the opposite direction, a 40-foot tornado vortex spinning with a ceiling-mounted tesla coil firing behind it. Another awe-inspiring moment used in this study is the reveal of the U-505 Unterseeboot, or U-boat (submarine). Guests enter the U-boat gallery after walking down a dark, sinking, narrow pathway (symbolically representing a submerging submarine) describing events leading up to the real life capture of the U-boat in 1944. The dark pathway opens up into a large gallery with the bow of the boat directly in front at eye level. Guests then walk down a ramp along the length of the submarine into a space presenting interactive exhibits.

\section{The Present Studies}

We present two studies of awe within a science museum context. The first study examined how awe differed across locations within a museum and its relationship with prior knowledge. The second study expanded the investigation to also examine the relationship between awe and skeptical and aesthetic thinking. Our first hypothesis was that awe would differ across within the museum and would be higher within specifically targeted exhibits than compared to a baseline condition. Our second hypothesis was that greater levels of awe would be positively related to higher scores on our skeptical and aesthetic thinking tasks. We used similar instruments in both studies as an additional check of reliability. We also placed special emphasis on the impact of negative associations with awe, something understudied in the literature.

\section{Study 1}

In Study 1, we sampled three locations in the MSI-Chicago to see if there is evidence of awe in the museum and whether it changed based on location design. To measure positively valenced awe, we chose the museum's rotunda. For negatively valenced awe, we chose the U-505 exhibit. Both target locations were expected to manifest the known elicitors of awe (Keltner \& 
Haidt, 2003; Shiota, Keltner, \& Mossman, 2007): physical vastness in both cases, but also aesthetic beauty in the case of the rotunda and historical significance in the case of the U-505. Our baseline location was a parking garage, which allowed us to collect data from museum guests before they entered the museum and interacted with any exhibits and we assumed would show low levels of positive and negative awe. We expected the target locations to elicit greater awe than the baseline locations. We were also interested in whether the nature of the awe experience would differ across locations.

In addition, we explored the role of prior knowledge in how one experiences awe. Knowledge can help individuals understand the complexity of their experience (Caranfa, 2003; Ecklund \& Long, 2011; Krause \& Hayward, 2015). In addition, background knowledge scaffolds the experience in such a way that individuals are able to recognize more precisely what they do not know - to locate and identify gaps in their knowledge. Prior knowledge can also help one appreciate how rare a particular experience can be. Awe arises in response to perceiving vastness and being motivated to make sense of the experience (Keltner \& Haidt, 2003). To the extent that knowledge can facilitate the comprehension of vastness and the recognition of a need for sensemaking, it should heighten the awe experience.

\section{Method}

Participants. Participants were 288 museum guests recruited from the museum floor $(\mathrm{n}=$ 182) and parking garage $(n=106)$. Participant demographics are presented in Table 1 for both Studies 1 and 2. As a matter of policy, as of 2017, the Museum no longer asks race/ethnicity questions unless it is fundamental to the research question. However, a separate 2018 internal study established that this museum's guest population self-identifies as $64 \%$ White, $12 \%$ Latinx, 12\% Asian and Asian ethnicities, 8\% Black or African American, 1\% American Indian or 
Alaskan Native, 1\% Middle Eastern or North African, 1\% Native Hawaiian or Other Pacific Islander and $1 \%$ other race or origins. This study was approved by the museum's Institutional Review Board.

Participants. Participants were 292 museum guests recruited from the museum floor. Participant demographics are presented in Table 1 for both Studies 1 and 2.

As a matter of policy, as of 2017, the Museum no longer asks race/ethnicity questions unless it is fundamental to the research question. However, a separate 2018 internal study established that this museum's guest population self-identifies as $64 \%$ White, $12 \%$ Latinx, $12 \%$ Asian and Asian ethnicities, $8 \%$ Black or African American, 1\% American Indian or Alaskan Native, $1 \%$ Middle Eastern or North African, $1 \%$ Native Hawaiian or Other Pacific Islander and $1 \%$ other race or origins. This study was approved by the museum's Institutional Review Board.

Table 1

Sample Demographics, Studies 1 and 2

\begin{tabular}{|c|c|c|}
\hline & $\begin{array}{c}\text { Study 1 } \\
(\mathrm{N}=288) \\
\end{array}$ & $\begin{array}{c}\text { Study } 2 \\
(\mathrm{~N}=708)\end{array}$ \\
\hline \multicolumn{3}{|l|}{ Age } \\
\hline Mean (SD) in years & $33.8(16.9)$ & $40.2(15.4)$ \\
\hline Range & $12-83$ & $15-100$ \\
\hline \multicolumn{3}{|l|}{ Gender } \\
\hline Female & 169 & 374 \\
\hline Male & 114 & 318 \\
\hline Nonbinary/Other & - & 2 \\
\hline Unspecified & 6 & 8 \\
\hline
\end{tabular}

Procedure. Materials were mostly administered via tablet devices, though occasionally paper surveys were used for accessibility reasons. Museum guests were approached in three separate locations within MSI: the parking garage, the rotunda, or the U-505 exhibit. For the garage, guests were recruited as as they approached the museum's doors after walking through the garage. At the rotunda, guests were approached as they were exiting the rotunda to enter 
another exhibit. An attempt was made to target guests who had just entered the rotunda for the first time, by looking for guests who arrived via an escalator from the main hall and who paused to get their bearings upon entering the space. U-505 guests were recruited after they had walked down a pathway that curved around the submarine. Participants completed the survey unsupervised and at their own pace. Participation in the research study was voluntary; however, they were offered free admission or a small science-themed gift ( $\sim \$ 3$ value) as an incentive. The survey was mostly distributed via tablet devices, except for a handful of guests who filled out a written survey for accessibility reasons. Following the completion of all tasks, participants were debriefed and compensated accordingly.

Awe-related emotions. Participants rated the extent to which they experienced each of nine awe-related emotions (awe, confusion, amazement, disorientation, wonder, fascination, astonishment, curiosity, and bewilderment) while walking through the target location (garage, rotunda, U-505), along a scale anchored from 0 (not at all) to 6 (very much); item order was randomized.

Momentary awe. Participants completed an 18-item Situational Awe Scale (SAS; Author, Author, Author, Author, \& Author, under revision). Reflecting the need to recognize and study the full complexity of an emotion (Pekrun et al., 2007), the SAS was designed to measure all aspects of awe, including some of its negative connotations. Its items reflect four facets of awe: liberation/connection (e.g., "I felt psychologically connected to everyone/everything around me"), oppression/isolation (e.g., "Everything seemed disjointed"), chills (e.g., "I felt chills), and diminished sense of self (e.g., "I felt like I was trivial in the grand scheme of things"). Participants rated the extent to which they disagreed versus agreed with each statement as it 
applied to how they felt while walking through the target location, along a 7-point scale anchored by -3 (disagree strongly) and +3 (agree strongly); item order was randomized.

Dispositional awe. Participants completed the awe subscale of the Dispositional Positive Emotion Scale (DPES-awe; Shiota, Keltner, \& John et al., 2006)They rated the extent to which they disagreed versus agreed with six items such as "I often feel awe" and "I feel wonder almost every day" as they applied to "normal daily life." Ratings were made along a 7-point scale anchored by -3 (disagree strongly) and +3 (agree strongly); item order was randomized.

Prior knowledge and learning enjoyment. Participants in the rotunda and the U-505 exhibit (but not the parking garage) responded to several items designed to reflect cognitive versus affective aspects of engagement. Specifically, they responded to two items assessing their self-perceived knowledge about location-relevant topics: "To what extent do you consider yourself knowledgeable about art [architecture]?" in the rotunda, and "To what extent do you consider yourself knowledgeable about military history [military technology]?” in the U-505 exhibit. They also responded to two items assessing their self-reported enjoyment of learning about location-relevant topics: "To what extent do you enjoy learning about art [architecture]?" in the rotunda and "To what extent do you enjoy learning about military history [military technology]?" in the U-505 exhibit. All ratings were made along 7-point scales anchored by 0 (not at all) and 6 (very much). ${ }^{1}$

\footnotetext{
${ }^{1}$ A critical thinking task was also included. Participants responded to the yes/no question, "Do you believe climate change is real and human activity is partially responsible for it?". They were then asked to provide evidence for their answer, which was intended to be coded as "strong" versus "weak" depending on whether the evidence reflected elaborated scientific knowledge versus non-elaborated reasons that did no more than reiterate subjective evaluations and emotions. Analysis was to reflect that one aspect of critical thinking is the ability to distinguish between strong and weak arguments (Griskevicius, Shiota, \& Neufeld, 2010). Unfortunately, so few participants provided valid responses (most responses were too short or provided no
} 
Demographic information. Participants reported their age and gender. They were also asked whether they had visited any other museums, zoos, or aquariums in the previous seven days, and to indicate on a checklist any other MSI exhibits they had visited that day prior to completing the survey.

\section{Results}

Scale descriptives for both studies are presented in Table 2. Inter-scale correlations and descriptive statistics for awe-related emotions and momentary awe as a function of target location are presented in Tables 3 and 4, respectively. Unless otherwise indicated, these latter scores were analyzed using analysis of variance (ANOVA) as a function of target location (garage, rotunda, U-505). Statistically significant main effects were probed with Bonferronicorrected $t$-tests. Note that missing/partial data were treated using listwise deletion procedures, resulting in small differences in sample sizes (and thus degrees of freedom) across analyses.

Do awe-related emotions vary as a function of context? To measure relatedness between items, we conducted an exploratory factor analysis on participants' awe-related emotion ratings, using oblimin rotation and maximum likelihood estimation for data extraction. The analysis yielded three factors, although one of the factors included items that loaded more strongly and more thematically onto another factor. We thus chose to calculate two factors, which we labelled according to the strongest contributing item: amazement (amazement, awe, astonishment, curiosity, fascination, wonder, and, surprisingly, bewilderment; Cronbach's $\alpha=$ .902 , inter-item $r=.26-.76$ ) and disorientation (confusion, disorientation; Cronbach's $\alpha=.78, r$ $=.65)$.

evidence) to the open-ended reason question that we were unable to reliably code and analyze the data. Those raw answers are available upon request. 
A MANOVA on awe-related emotion scores as a function of target location revealed a reliable multivariate main effect of location, $F(4,568)=10.63, p<.001, \eta^{2} p=.070$. At the univariate level, amazement differed reliably as a function of location, $F(2,284)=16.46, p<$ $.001, \eta^{2} \mathrm{p}=.104$, as did disorientation, $F(2,284)=3.61, p=.028$. However, participants in the rotunda and the U-505 exhibit both reported higher amazement relative to participants in the parking garage, both $p<.001$; amazement did not differ between the rotunda and the U-505 exhibit, $p=1$. In terms of disorientation, the only reliable effect was that participants in the U505 exhibit reported less disorientation than participants in the parking garage, $p=.037$, all other $p \geq .11$.

Does momentary awe vary as a function of context? A confirmatory factor analysis of the four facets of awe determined by Author et al. (under revision) yielded only marginal support for the original structural model $(\mathrm{CFI}=.893, \mathrm{RMSEA}=.072)$, but a follow-up exploratory factor analysis using maximum likelihood extraction and oblimin rotation suggested that items loaded as predicted for three of the four factors (the exception being the diminished-self factor ${ }^{2}$ ). Thus, we elected to calculate the subscale scores as originally suggested: liberation/connection (Cronbach's $\alpha=.83$, inter-item $r=.36-.57) ;$ oppression/isolation (Cronbach's $\alpha=.81$, inter-item $r=.398-.55)$, chills (Cronbach's $\alpha=.85$, inter-item $r=.49-.68)$, and diminished self (Cronbach's $\alpha=.51$, inter-item $r=.22-.31$ ).

\footnotetext{
${ }^{2}$ We elected to keep the diminished-self factor because it remains theoretically interesting but its reliability might be compromised by the fact that it contains only three items.
} 


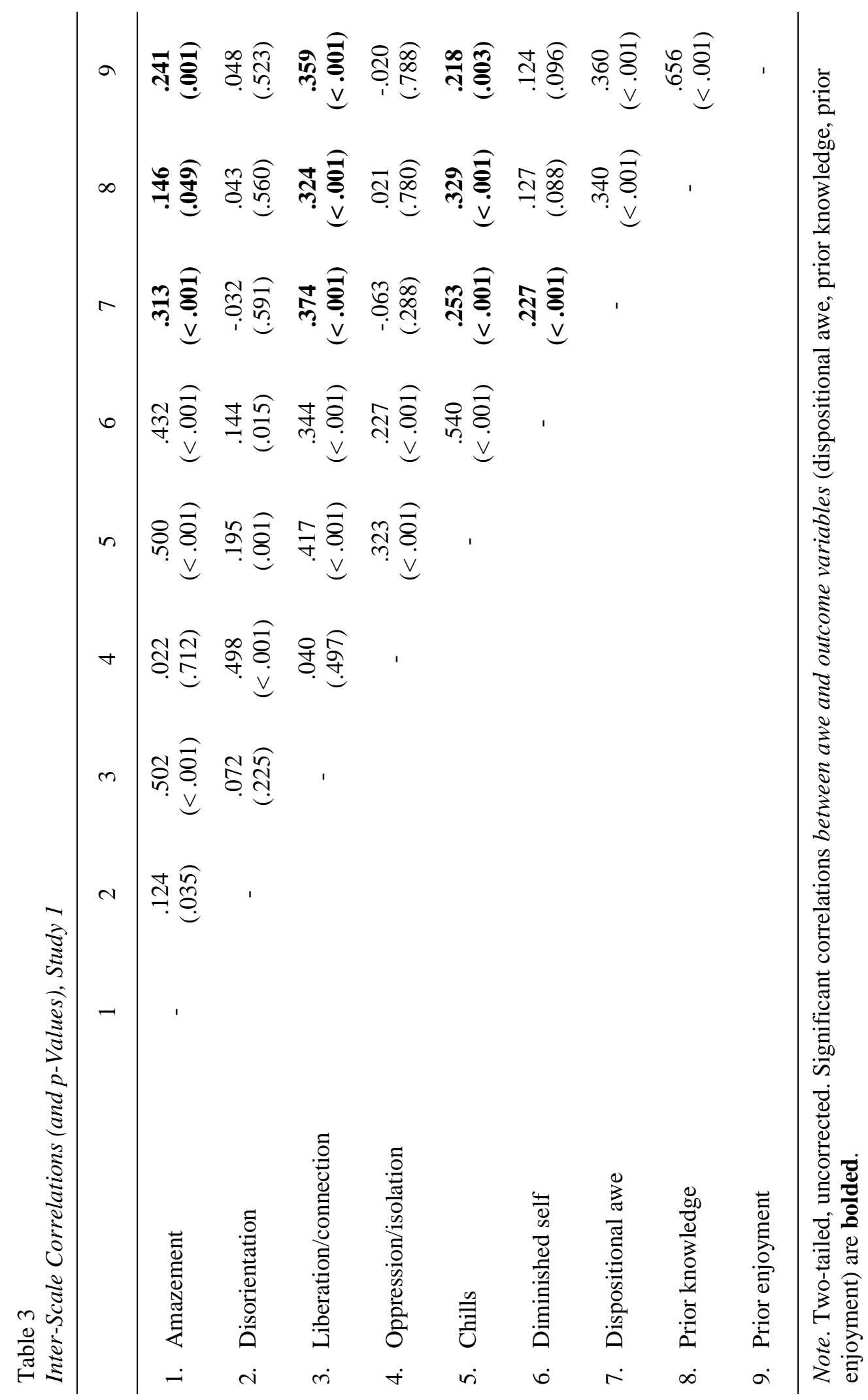


Table 4

Awe Score Means (and Standard Deviations) as a Function of Location, Study 1

\begin{tabular}{lllc}
\hline & $\begin{array}{c}\text { Garage } \\
(\mathrm{n}=106)\end{array}$ & $\begin{array}{c}\text { Rotunda } \\
(\mathrm{n}=90)\end{array}$ & $\begin{array}{c}\text { U-505 } \\
(\mathrm{n}=92)\end{array}$ \\
\hline Awe-Related Emotions & & & \\
Amazement & $3.55(1.58)$ & $4.39(1.09)$ & $1.45(0.91)$ \\
Disorientation & $1.68(1.62)$ & $1.61(1.41)$ & \\
Momentary Awe & & & $0.61(1.079)$ \\
Liberation/connection & $0.73(1.22)$ & $0.64(0.99)$ & $-0.98(1.23)$ \\
Oppression/isolation & $-1.15(1.33)$ & $-1.58(1.106)$ & $0.11(1.35)$ \\
Chills & $-0.69(1.59)$ & $0.26(1.38)$ & $0.66(1.19)$ \\
Small self & $0.09(1.21)$ & $0.78(1.02)$ &
\end{tabular}

Note. Possible range $=0$ to 6 for awe-related emotions; -3 to +3 for momentary awe.

A MANOVA on momentary awe scores as a function of target location yielded a significant effect of location, $F(8,566)=8.65, p<.001, \eta^{2}{ }_{p}=.109$. At the univariate level, this effect was not reliable for liberation/connection, $F(2,285)=0.34, p=.72, \eta^{2} p=.002$. In contrast, all three remaining facets yielded reliable univariate effects: oppression/isolation, $F(2$, $285)=5.89, p=.003, \eta_{\mathrm{p}}^{2}=.040 ;$ chills, $F(2,285)=12.19, p<.001, \eta_{\mathrm{p}}^{2}=.079 ;$ diminished self, $F(2,285)=10.204, p<.001, \eta_{\mathrm{p}}^{2}=.067$. Participants in the rotunda and the U-505 exhibit reported stronger chills and diminished-self perceptions than did participants in the parking garage, all $p \leq .002$; reported chills and diminished-self perceptions did not differ between the rotunda and U-505 exhibit, both $p=1$. Participants in the U-505 exhibited also reported more oppression/isolation than did participants in the rotunda, $p=.004$; participants in the parking 
garage reported intermediate levels of oppression/isolation that did not differ from either target location, $p \geq .043$.

How does dispositional awe relate to momentary awe experience? Dispositional awe scores were calculated by averaging across the six DPES-awe items (Cronbach's $\alpha=.78$, interitem $r=.19-.500)$. As Table 3 indicates, dispositional awe was associated with all positive variants and facets of awe: To the extent that participants reported a stronger tendency to experience awe, they also reported higher levels of liberation/connection, stronger chills, stronger diminished-self perceptions, and stronger amazement.

\section{How do prior knowledge and learning enjoyment relate to momentary awe} experience? We averaged across participants' ratings separately for knowledge items (Cronbach's $\alpha=.79, r=.65$ ) and learning enjoyment items (Cronbach's $\alpha=.82, r=.698)$. As indicated in Table 3, prior learning enjoyment correlated positively with amazement. In addition, the analysis revealed positive associations between both prior knowledge and learning enjoyment, and two facets of awe: To the extent that participants reported more prior knowledge and learning enjoyment, they also reported higher levels of liberation/connection and stronger chills.

We used a linear regression model to predict the effect of prior knowledge and learning enjoyment on momentary awe. Feelings of liberation/connection were predicted by both prior knowledge $(\beta=0.151, \mathrm{SE}=.066, p=.022)$ and prior learning enjoyment $(\beta=0.145, \mathrm{SE}=.067$, $p=.031)$, and that chills were predicted by prior knowledge $(\beta=0.33, \mathrm{SE}=.088, p<.001)$ but not learning enjoyment $(\beta=-.040, \mathrm{SE}=.089, p=.66)$.

\section{Discussion}


The goal of Study 1 was to confirm whether we could reliably measure different levels of awe in science museum guests as a function of the location in which they reflected on their experience. For positive awe, we chose a location (the rotunda) that was vast, beautiful and hopeful. For negative awe, we chose another location (the U-505 exhibit) that was also vast, but associated with negative topics (war) and designed to give a sense of the extreme, claustrophobic lifestyle sailors experienced while on board. Indeed, we demonstrated that the positive-awe location, relative to baseline, evoked stronger feelings of amazement, stronger chills, and a diminished sense of self. The negative-awe location evoked the same reactions, as well as stronger feelings of oppression/isolation.

We also conducted a preliminary exploration of the relationship between prior knowledge of and learning enjoyment related to location-relevant topics. If awe is indeed an epistemic or knowledge emotion, then it should be related to how much individuals engage with the relevant information. Indeed, we found that self-reported pre-visit knowledge of location-relevant topics (art and architecture in the rotunda, or military history and technology in the U-505 exhibit) were associated with stronger feelings of liberation/connection and chills. Pre-visit enjoyment of learning about location-relevant topics was also associated with stronger liberation/connection and chills, but also with greater amazement. This was an unexpected result. Awe is often associated with elements of surprise and violations of expectation (Valdesolo, et al. 2017), yet we find that prior knowledge actually increased awe-perhaps due to a better ability to appreciate what they were experiencing.

The similarities and differences in experienced awe in the rotunda and U-505 exhibit highlight the importance of examining both positive and negative variants of awe: Although only the U-505 elicited stronger feelings of oppression/isolation relative to baseline, both the U-505 
and the rotunda elicited stronger chills and diminished-self perceptions. This pattern is informative regarding the nature of awe: Although we might colloquially think of awe as a positive emotion, it can nonetheless include a negative component.

In sum, Study 1 confirmed that we could reliably differentiate awe experiences as a function of exhibit space. It also provided some preliminary insight into the role of engagement in the awe experience. The results suggested that the cognitive aspect of engagement—prior knowledge — was associated most strongly with experiencing chills; the affective aspect of engagement — prior learning enjoyment—was associated most strongly with feelings of liberation/connection. In focusing on prior knowledge and learning enjoyment, however, our results speak more to whether engagement predicts awe, ${ }^{3}$ rather than on the question of whether awe increases elements of critical thinking; we sought to address the latter in Study 2.

\section{Study 2}

In Study 2, we investigated awe as a predictor of skeptical and aesthetic thinking - two aspects of critical thinking. For a subset of participants, we assessed self-reported skepticism, operationalized in terms of an enjoyment of learning, a preference for considered and unhurried judgment, and a reliance on one's own judgment. For a different subset of participants, we analyzed critical thinking, operationalized in terms of their responses to a set of visual stimuli. We sought to demonstrate that momentary awe would be associated with a greater self-reported preference for critical thinking, and deeper analyses of visual stimuli that reflected greater engagement with the stimuli.

\footnotetext{
${ }^{3}$ Of course, our correlational design does not allow us to make strong inferences about causality, and retrospective reports might be biased by ongoing experience.
} 
Our critical thinking measure was based on the Visual Thinking Strategies (VTS) framework, which is informed by the stages of aesthetic development theory (DeSantis \& Housen, 2000). This framework supports evidentiary reasoning by encouraging learners to “observe carefully, evaluate, synthesize, justify and speculate” (Housen, 2002, p.101). The VTS framework applies aspects of Piaget's stages of cognitive development and Vygotsky's zone of proximal development to describe the growth of aesthetic appreciation and cognition, which occurs across five distinct stages of thinking (Housen, 2007). We focused on two of those stages that the majority of museum guests are likely to experience. The first, Accountive, describes individuals making simple, concrete, and sometimes egocentric observations of art work and exhibits that may be used to tell narratives. In the second stage, Constructive, individuals begin to build a framework of what they see using their perception, knowledge, and values (Yenawine, 1999; Housen, 2002, 2007).

VTS was first designed as a curriculum to help art educators develop aesthetic understanding in their students and the art viewing public (Housen, 2002). Its core activity entails exposing students to visual art work and posing a series of open-ended questions: "What is going on here?", "What do you see that makes you say that?", and "What more can you find?" (Housen, 2002; Yenawine, 1999). VTS is very commonly used in the art education field. However, its use has now grown into non-art disciplines. Recently, it has been applied to science education contexts to promote observation and communication skills (Wellbery \& McAteer, 2015, Yenawine, 2013), interdisciplinary health learning programs (Klugman \& BeckmannMendez, 2015), pharmacy programs (Ryan, 2013), and nursing programs (Reilly, Ring \& Duke, 2005). It has been used to teach critical thinking skills to dental and medical school students (Curtin \& McConnell, 2017; Anderson, 2018) and to measure the development of scientific 
thinking skills in children (Foss, 2014). VTS is currently being adapted as a curriculum framework for science museums and classrooms (IMLS, 2016).

As an assessment framework, VTS analyses have been primarily focused on the content of interviews conducted with students using the previous three VTS questions as prompts. VTS has also more recently been administered within constructed response writing tasks (Curva et al., 2005, DeSantis 2007, DeSantis 2009, Egan \& Grobe 2014; Foss, 2014; Greene, Kisida, \& Bowen, 2014). Responses are typically analyzed for associations between elements that students saw in the art or objects being observed and/or the quality of the direct evidence they linked to their observations. These associations have been shown to reflect critical thinking skills such as making critical observations, interpreting identity and context of a scene, comparing elements in an image, thinking flexibly about meaning and identifying problems (Adams, Foutz, Luke, \& Stein, 2006;). Additionally, standardized test scores have been used to measure a VTS-based curriculum's impact on students' general academic achievement (Adams, et al., 2006; Curva et al., 2005).

In Study 2, we sampled four locations at the museum. We approached guests not only in the parking garage and rotunda as in Study 1, but also at a separate entrance, located in the ground floor entrance kiosk and in the main hall as they were leaving. The entrance kiosk is situated in a park setting area surrounded by a large grassy knoll, playgrounds, bus/car drop off ribbon and the shore of Lake Michigan. It is the main entrance venue for guests who arrive via mass transit, bicycle and walking, taxi and ride sharing services (about 50\%). It was chosen to measure any impact the Museum's architecture itself may have on awe and provide another baseline to represent guests' experience. The main hall is where tickets are purchased and was chosen to provide a second location that should evoke positive awe (with its vastness and a high, 
arched ceiling); we also wanted to provide an end-of-day measure, to provide preliminary data on whether awe diminishes with exposure.

\section{Method}

Participants. Participants were 708 museum guests, recruited and compensated as in Study 1. Participant demographics are presented in Table 1. This study was approved by the museum's Institutional Review Board.

Procedure. Procedures were as in Study 1 unless otherwise noted. Museum guests were approached in four separate locations: in the parking garage or at the ground floor entrance kiosk before they entered the museum, on their way out of the rotunda to enter an exhibit, or in the main hall as they were leaving the museum.

Data collection was conducted in several waves, with participants in all waves first completing the awe-related emotion and momentary awe measures as in Study 1. Participants in one wave of data collection $(n=456)$ then completed a critical thinking pilot ${ }^{4}$ and a skepticism measure prior to completing the art-/architecture-oriented prior knowledge and enjoyment measure; participants in the other wave of data collection $(n=188)$ completed the art/architecture-oriented prior knowledge and enjoyment measure from Study 1, followed by the aesthetic thinking measure. ${ }^{5}$ The remaining participants $(n=64)$ completed only the awe-related emotions, momentary awe, and prior knowledge and enjoyment measures. Finally, all participants provided demographic information.

\footnotetext{
${ }^{4} \mathrm{We}$ do not report the pilot for this paper because the instrument did not pass a number of psychometric validation tests. Participants were asked to rate the strength of a set of arguments in favor of light pollution as a topic of societal and scientific importance.

${ }^{5}$ Due to a programming error, a subset of participants in the second wave of data collection (those approached in the parking garage or at the entrance kiosk) received only three of the four prior knowledge and learning enjoyment items; the item assessing learning enjoyment related to architecture was mistakenly omitted.
} 
Skepticism. The Professional Skepticism Scale (PSS; Hurtt, 2010) contains 30 items that cover six components of skepticism. We included 20 items comprising four of the factors: search for knowledge (e.g., "I think that learning is exciting"); suspension of judgment (e.g., "I take my time when making decisions"); self-determination (e.g., "I tend to immediately accept what other people tell me"; reverse-coded); and questioning mind (e.g., "I frequently question things that I see or hear"). Ratings were made along a 7-point scale anchored by -3 (disagree strongly) and +3 (agree strongly); item order was randomized.

Visual thinking. Each participant was shown two of three science-themed images (see Figure 1), chosen randomly. Beneath each image were the three VTS prompts: "What is going on here? (Try to write at least 50 words)", followed by "What do you see that makes you think that? (Try to write at least 25 words)", and then "What else is going on here? (Try to write at least 50 words)". Word length suggestions were added after pilot testing revealed brevity in initial guest responses.

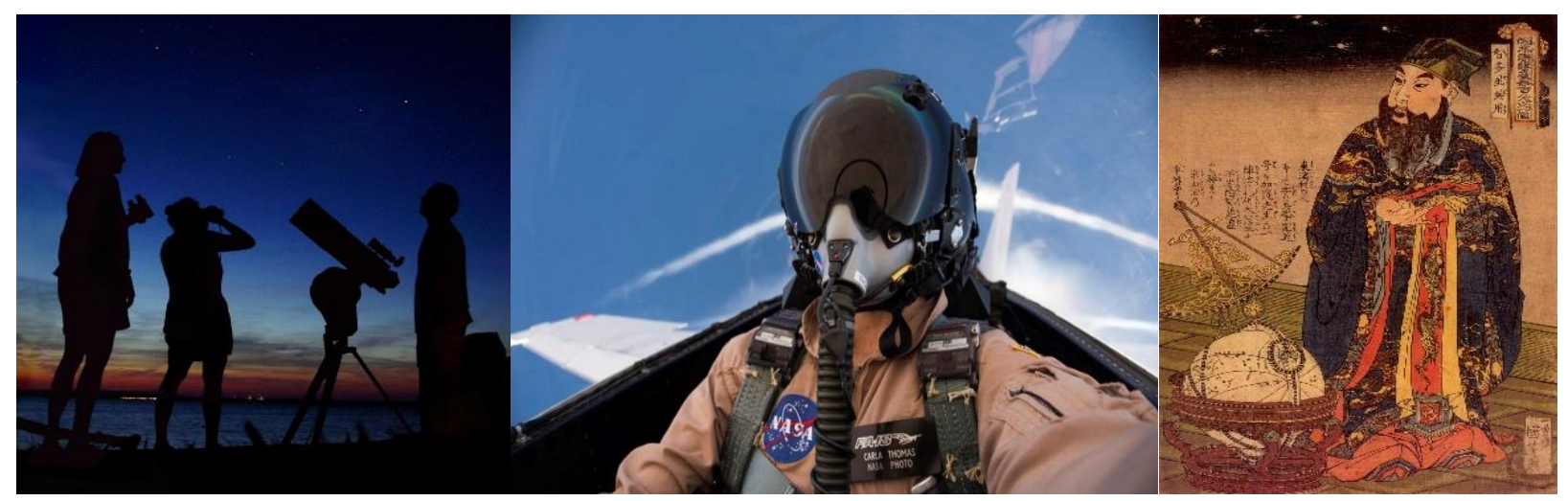

Figure 1. Images used for the Visual Thinking Strategies measure. (Captions, left to right: Halfblue [CC-BY-SA-3.0], via Wikimedia Commons, NASA/Ken Ulbrich, Utagawa Kuniyoshi [Public domain], via Wikimedia Commons).

\section{Results}


Scale descriptives are presented in Table 2. Inter-scale correlations and descriptive statistics for awe-related emotions and momentary awe as a function of target location are presented in Tables 5-6, respectively. Unless otherwise indicated, these latter scores were analyzed using ANOVA as a function of target location (garage, entrance kiosk, main hallarriving, rotunda, main hall-leaving). Statistically significant main effects were probed with Bonferroni-corrected $t$-tests. As in Study 1, missing/partial data were treated using listwise deletion procedures, resulting in small differences in sample sizes (and thus degrees of freedom) across analyses.

Do awe-related emotions vary as a function of context? As in Study 1, to reduce the effect of inter-item correlations, we conducted an exploratory factor analysis on participants' awe-related emotion ratings, using oblimin rotation and maximum likelihood estimation for data extraction. The analysis yielded three factors, which we again labelled according to the strongest contributing item: amazement (amazement, astonishment, awe; Cronbach's $\alpha=.89$, inter-item $r$ $=.602-.75$ ), disorientation (confusion, disorientation; Cronbach's $\alpha=.75, r=.595$ ), and curiosity (curiosity, fascination; Cronbach's $\alpha=.79, r=.66$ ). Two items (wonder, bewilderment) each loaded onto two factors with similar factor loadings; inspection of the fit of these items with the separate factors yielded no clear decisions as to where they belonged, so we elected to omit them from the analysis. 


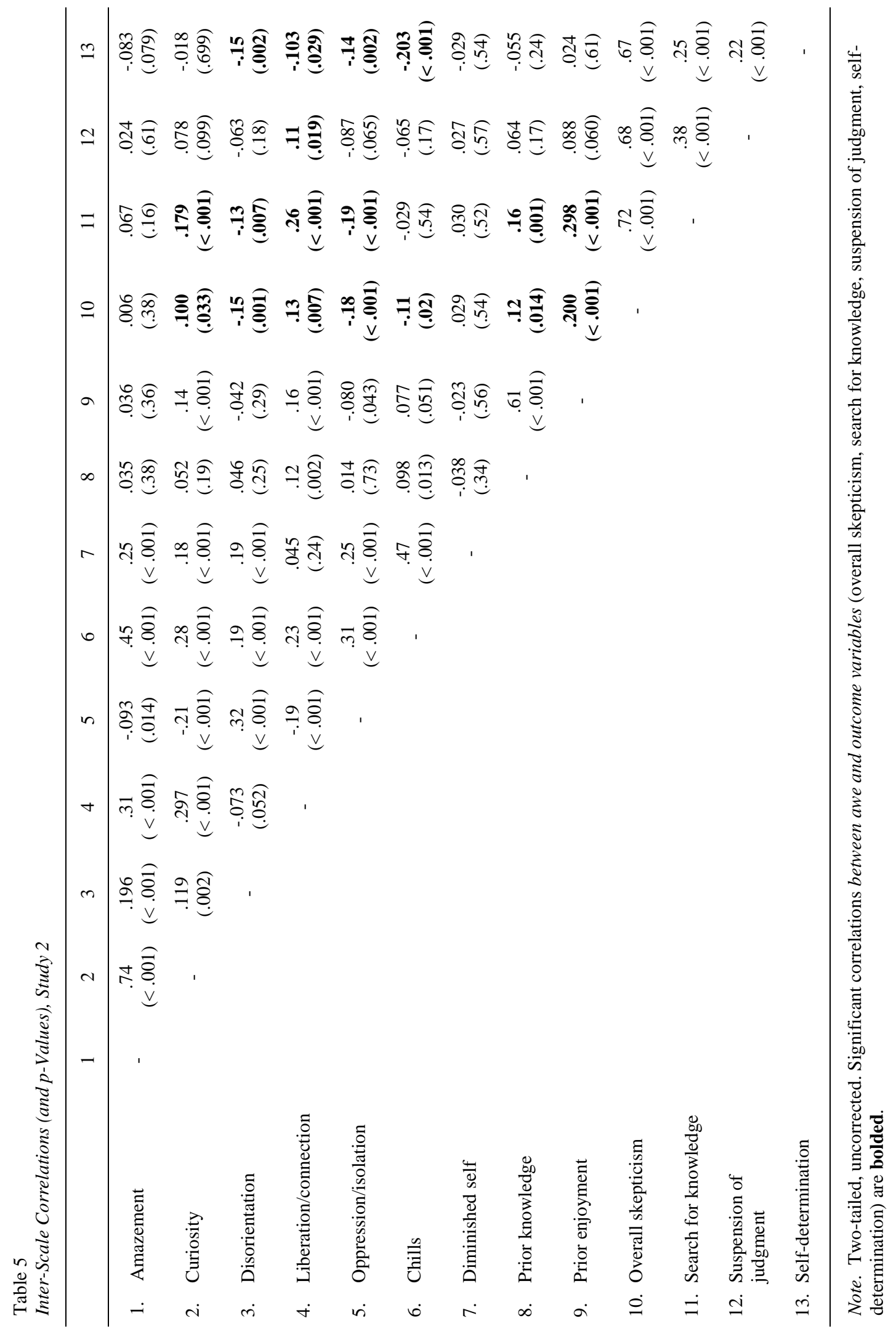


Table 6

Awe Score Means (and Standard Deviations) as a Function of Location, Study 2

$\begin{array}{ccccc}\text { Garage } & \begin{array}{c}\text { Entrance } \\ \text { Kiosk }\end{array} & \begin{array}{c}\text { Main Hall } \\ \text { (Arriving) }\end{array} & \text { Rotunda } & \text { Main Hall } \\ (\mathrm{n}=196) & (\mathrm{n}=171) & (\mathrm{n}=64) & (\mathrm{n}=165) & (\mathrm{n}=108)\end{array}$

Awe-Related Emotions

$\begin{array}{lccccc}\text { Amazement } & 2.800 & 2.65 & 3.47 & 4.08 & 4.25 \\ & (1.68) & (1.63) & (1.54) & (1.32) & (1.24) \\ \text { Curiosity } & 3.96 & 3.86 & 4.500 & 4.82 & 4.597 \\ & (1.62) & (1.57) & (1.32) & (1.08) & (1.09) \\ \text { Disorientation } & 1.26 & 0.97 & 1.13 & 1.82 & 1.27 \\ & (1.405) & (1.23) & (1.46) & (1.39) & (1.14)\end{array}$

Momentary Awe

$\begin{array}{lccccc}\text { Liberation/connection } & 0.79 & 0.94 & 0.78 & 0.601 & 0.71 \\ & (1.08) & (1.07) & (0.99) & (0.92) & (0.92) \\ \text { Oppression/isolation } & -1.23 & -1.83 & -1.76 & -1.61 & -1.44 \\ & (1.24) & (1.17) & (1.25) & (1.16) & (1.11) \\ \text { Chills } & -1.05 & -1.63 & -1.15 & -0.34 & -0.42 \\ & (1.34) & (1.43) & (1.42) & (1.14) & (1.32) \\ \text { Small self } & 0.198 & -0.28 & 0.18 & 0.71 & 0.65 \\ & (1.22) & (1.42) & (1.22) & (1.06) & (1.17)\end{array}$

Note. Possible range $=0$ to 6 for awe-related emotions; -3 to +3 for momentary awe.

A multivariate ANOVA on awe-related emotion scores as a function of target location yielded a significant effect of location, $F(12,2094)=13.55, p<.001, \eta^{2}{ }_{p}=.072$. At the univariate level, three scores yielded reliable univariate effects: amazement, $F(4,698)=35.14, p$ $<.001, \eta_{\mathrm{p}}^{2}=.168 ;$ disorientation, $F(4,698)=9.23, p<.001, \eta_{\mathrm{p}}^{2}=.050 ;$ curiosity, $F(4,698)=$ $14.49, p<.001, \eta_{\mathrm{p}}^{2}=.077$. Participants in the rotunda and leaving the main hall reported more amazement and curiosity than did participants in the parking garage or at the entrance kiosk, all $p$ $<.001$. Participants in the main hall prior to leaving the museum also reported more amazement 
than did participant in the main hall entering the museum, $p=.010$. Participants in the rotunda also reported more disorientation than did participants in all other locations, all $p \leq .009$. This is perhaps because they were overwhelmed by the large number of exhibit options displayed before them combined by the design of the heavy-sensory load, multi-level space.

Does momentary awe vary as a function of context? As in Study 1 , a confirmatory factor analysis of the four facets of awe determined by Author et al. (under revision) yielded only marginal support for the original structural model $(\mathrm{CFI}=.87, \mathrm{RMSEA}=.0787)$, but a follow-up exploratory factor analysis using maximum likelihood extraction and oblimin rotation again suggested that items generally loaded as predicted on the four factors. Two items (free, breath taken) each loaded onto two factors (liberation/connection and oppression/isolation, and chills and diminished-self, respectively), but the stronger factor loadings were on the appropriate subscales. Thus, we elected to calculate the subscale scores as originally suggested: liberation/connection (Cronbach's $\alpha=.79$, inter-item $r=.26-.66$ ); oppression/isolation (Cronbach's $\alpha=.83$, inter-item $r=.41-.57)$, chills (Cronbach's $\alpha=.84$, inter-item $r=.46-.71$ ), and diminished self (Cronbach's $\alpha=.54$, inter-item $r=.27-.31$ ).

A multivariate ANOVA on momentary awe scores as a function of target location yielded a significant effect of location, $F(16,2796)=11.11, p<.001, \eta^{2}=.060$. At the univariate level, this effect was reliable for liberation/connection, $F(4,699)=2.52, p=.040, \eta^{2}{ }_{p}=.014$, although the only significant effect was that participants in the rotunda reported less liberation/connection than participants at the entrance kiosk, $p=.021$, all other $p \geq .62$.

All three remaining facets also yielded reliable univariate effects: oppression/isolation, $F(4,699)=6.754, p<.001, \eta_{\mathrm{p}}^{2}=.037 ;$ chills, $F(4,699)=25.02, p<.001, \eta_{\mathrm{p}}^{2}=.125 ;$ diminished self, $F(4,699)=16.601, p<.001, \eta^{2}=.087$. Participants in the rotunda reported stronger chills 
and diminished-self perceptions than participants in the parking garage, at the entrance kiosk, or in the main hall arriving at the museum, all $p \leq .035$, and less oppression/isolation than participants in the parking garage, $p<.001$. Participants in the main hall leaving the museum also reported stronger chills and diminished-self perceptions than participants in the parking garage or at the entrance kiosk, both $p \leq .023$, and stronger chills than participants in the main hall arriving at the museum, $p=.006$. Surprisingly, participants in the rotunda or in the main hall leaving the museum reported more oppression/isolation than participants at the entrance kiosk or in the main hall arriving at the museum, all $p \leq .006$.

\section{How do prior knowledge and learning enjoyment relate to momentary awe}

experience? As in Study 1, we averaged across participants' ratings separately for knowledge items (Cronbach's $\alpha=.82, r=.695$ ) and learning enjoyment items (Cronbach's $\alpha=.74, r=.57$ ). As in Study 1, both knowledge and learning enjoyment were positively associated with momentary liberation/connection: To the extent that participants reported more prior knowledge and interest, they also reported higher levels of liberation/connection. A regression analysis to control for the intercorrelation between prior knowledge and learning enjoyment revealed, as in Study 1 , that feelings of liberation/connection were predicted by prior learning enjoyment $(\beta=$ $0.103, \mathrm{SE}=.044, p=.019)$ but not knowledge $(\beta=0.021, \mathrm{SE}=.042, p=.61)$.

The prior knowledge and learning enjoyment measures also showed some divergence: Participants who reported more prior knowledge about art/architecture also reported stronger chills (as in Study 1); participants who reported more prior learning enjoyment for art/architecture also reported stronger curiosity and less oppression/isolation.

How does skepticism relate to momentary awe experience? A confirmatory factor analysis did not provide evidence of adequate model fit $(\mathrm{CFI}=.88, \mathrm{RMSEA}=.0719)$, but a 
follow-up exploratory factor analysis using maximum likelihood extraction and oblimin rotation suggested that most items loaded as predicted on three of the four factors; problems were apparent with the questioning mind subscale, however, in that items purported to belong to other subscales instead loaded onto this subscale, with the result that the factor had no clear theme. Examining the internal consistency of the full 20-item scale yielded an acceptable Cronbach's $\alpha$ (.85); however, examination of the inter-item correlations suggested too broad a range of correlations and several correlations that were unacceptably low (i.e., <.10). In general, the factor structure supported the predicted structure, with three of the factors including only predicted items; however, two factors emerged with content (i.e., factor loadings) that included items from multiple theoretical subscales and that did not have clear themes. We thus decided to use not only the total score (averaged across the 20 items), but also to calculate factor scores for the three subscales where the evidence largely supported the theoretical factor content. We included only the items that loaded onto the subscales in the exploratory factor analysis: search for knowledge (5 of 6 items of the predicted items; Cronbach's $\alpha=.85$, inter-item $r=.43-.71$ ), suspension of judgment ( 4 of 5 of the predicted items; Cronbach's $\alpha=.67$, inter-item $r=.198-$ .42 ), and self-determination ( 4 of 5 of the predicted items; Cronbach's $\alpha=.81$, inter-item $r=$ $.37-.59)$

As depicted in Table 3, to the extent that participants reported more curiosity and liberation/connection, and less disorientation, oppression/isolation, and chills, they also reported more overall skepticism. A regression analysis controlling for the inter-correlations among the predictors revealed that chill and diminished-self perceptions both negatively predicted unique variance in overall skepticism scores. 
This pattern was largely replicated with the search for knowledge subscale, with the only exception that search for knowledge was unrelated to chills: To the extent that participants reported more curiosity and liberation/connection, and less disorientation and oppression/isolation, they also reported greater interest in learning. A regression analysis controlling for the inter-correlations among the predictors revealed that curiosity and liberation/connection both positively predicted unique variance in search for knowledge scores; surprisingly, amazement emerged as a negative predictor.

Suspension of judgment correlated only with liberation/connection, such that participants who reported stronger liberation/connection also reported a stronger preference for unhurried, carefully considered judgments.

As with overall skepticism, self-determination correlated negatively with disorientation, oppression/isolation, and chills: To the extent that participants reported more disorientation, oppression/isolation, and chills, they also reported a greater likelihood of reflexively accepting others' judgments. Interestingly, although overall skepticism correlated positively with liberation/connection, the reverse was true for self-determination: To the extent that participants reported more liberation/connection, they also reported less self-determination. A regression analysis controlling for the inter-correlations among the predictors revealed that chills and disorientation both negatively predicted unique variance in self-determination scores, and that feelings of liberation/connection positively predicted scores.

How does visual thinking relate to momentary awe experience? VTS responses were blind coded using a rubric with categories taken from a VTS study of critical thinking by Adams et al. (2006) (Table 7). Each category included three codes: 0 (missing or irrelevant data), 1 (category not present in response), and 2 (category present in response). In each category, the 
first 135 responses (19\%) were independently coded by two researchers who reached an interrater reliability of $86 \%-96 \%$ across categories. The remaining responses were coded by one of the researchers. For analysis purposes, 0 codes were removed and the remaining categories were recoded as 0 (category absent) and 1 (category present). Because each participant saw two images and were given three question prompts for each image, each guest had 6 items that were scored as either 0 or 1 .

We conducted exploratory analyses linking visual thinking and awe using separate hierarchical logistic regression models for each VTS. Guest ID was the random effect for all regression models. An omnibus model was run using each momentary awe factor to predict a summary of all the VTS codes. Separate models were then run using unique momentary awe factors to predict each VTS code.

The full results of the analyses are summarized in Table S1 of Supplementary Materials. We found that higher scores on the oppression/isolation factor significantly predicted lower scores on the composite VTS measure, $p=.01$. Thus, experiencing more oppression/isolation was associated with less visual thinking overall. In terms of the models of the individual VTS categories, higher diminished-self scores predicted higher scores in the VTS categories of Observation and Intention, $p=.008$ and .04 , respectively. That is, stronger diminished-self perceptions were associated with increased ability to describe the roles and actions of people and animals and generally narrating what is going on in the images. We also found that higher chills scores predicted higher scores in the Evaluate VTS category, $p=.03$. In other words, experiencing stronger chills was associated with an increased ability of guests to describe their personal opinion about the images. 
Table 7

Visual Thinking Strategies Critical Thinking Coding Rubric Adapted from Adams et al. (2006)

\begin{tabular}{|c|c|c|}
\hline Categorical Code & Definition & Examples \\
\hline Compare & $\begin{array}{l}\text { Comparing } \\
\text { things within } \\
\text { the image, } \\
\text { describing } \\
\text { patterns }\end{array}$ & $\begin{array}{l}\text { "A group of people are stargazing, though some } \\
\text { appear to be looking too low, so perhaps they are also } \\
\text { bird watching. They are looking in different } \\
\text { directions, so perhaps they are not part of the same } \\
\text { group." } \\
\text { "It also is most likely early summer or early fall as } \\
\text { some people are in shorts and the man is in pants." }\end{array}$ \\
\hline Interpret Object & $\begin{array}{l}\text { Interpreting } \\
\text { object use - } \\
\text { what they do } \\
\text { and how they } \\
\text { are used }\end{array}$ & $\begin{array}{l}\text { "A scholar is trying to educate his students in some } \\
\text { context by displaying the globe..." } \\
\text { "Contrails might indicate a barrel role." }\end{array}$ \\
\hline Interpret Identity & $\begin{array}{l}\text { Identifying } \\
\text { people, } \\
\text { relationships, } \\
\text { provenance of } \\
\text { objects }\end{array}$ & $\begin{array}{l}\text { "People are showing a mutual interest in star gazing. It } \\
\text { might be a social group on a class room setting or they } \\
\text { could be scientist researching." } \\
\text { "He may also be some sort of god. He may be in } \\
\text { charge of manipulating the stars and planets of the } \\
\text { universe." }\end{array}$ \\
\hline Evaluate & $\begin{array}{l}\text { Personal } \\
\text { opinion and } \\
\text { responses }\end{array}$ & $\begin{array}{l}\text { "She flies for NASA which is cool." } \\
\text { "The colors in the picture escalate the very being of } \\
\text { what a person can see or feel: the intensity of the } \\
\text { colors brings more to the art at hand." }\end{array}$ \\
\hline Flexible Thinking & $\begin{array}{l}\text { Using multiple } \\
\text { perspectives, } \\
\text { possibilities and } \\
\text { revisions to } \\
\text { thought }\end{array}$ & $\begin{array}{l}\text { "A NASA pilot is testing a new aircraft. She is in the } \\
\text { middle of a sick barrel roll. Probably she is at an air } \\
\text { show. Actually, this may be a false photo since her } \\
\text { name badge says NASA photo." } \\
\text { "People are showing a mutual interest in star gazing. It } \\
\text { might be a social group on a class room setting or they } \\
\text { could be scientist researching." }\end{array}$ \\
\hline
\end{tabular}




\section{Discussion}

In Study 2, we largely replicated the results of Study 1 in terms of participants' awe experiences in response to different museum locations and the associations between these experiences and their prior knowledge and interest in learning about location-relevant topics. Participants in the spaces expected to inspire awe (rotunda, main hall), relative to participants in the spaces not expected to do so (parking garage, entrance kiosk) expressed greater amazement, curiosity, chills, and diminished-self perceptions. Further, to the extent that participants reported more pre-visit knowledge and learning enjoyment, they expressed stronger liberation/connection, chills (knowledge only), and amazement (learning enjoyment only).

The knowledge and learning enjoyment results provided indirect evidence for a causal impact of learning on awe, but in Study 2 we were also able to provide some evidence for an impact of awe on learning-relevant variables. On a measure of visual thinking, stronger diminished-self perceptions were associated with improvements in describing the actions and intentions of others as seen in a visual image or artwork. Perhaps awe-related facilitation of an attentional shift away from the self toward others and the world supported increased critical appreciation and thinking about the image. The connection between observation codes and intention-diminished-self relationship is consistent with this idea. We also observed that stronger chills were associated with improvement in describing personal opinions, which might reflect the fact that this facet of awe is the one most closely linked to the self-centered (i.e., embodied) experience. Finally, we observed that stronger feelings of oppression/isolation were associated with lower overall visual thinking scores. This underscores the point that awe, although an epistemic emotion, might not always be a catalyst for interest in learning-especially when associated with negative aspects of awe. 
We also observed associations between awe and skepticism, operationalized in terms of an enjoyment of learning (search for knowledge), a preference for considered and unhurried judgment (suspension of judgment), and relying on one's own judgment (self-determination)— all of which are hallmarks of a willingness to engage in critical thought. We found that positive awe-greater curiosity and stronger liberation/connection—was associated with greater skepticism overall, and specifically with greater enjoyment of learning; liberation/connection was also associated with a preference for careful, unhurried judgment (but also, paradoxically, with a greater likelihood of accepting others' judgments). Negative awe-greater disorientation and stronger oppression/isolation—was associated with lower skepticism overall, and specifically with less enjoyment of learning (but also, paradoxically, with a lower likelihood of accepting others' judgments).

Interestingly, diminished-self perceptions were not associated with skepticism, and chills were associated with skepticism in surprising ways: Stronger chills were associated with less skepticism and a higher likelihood of accepting others' judgments. This facet of awe is understudied, but these findings might be less surprising than they seem at first glance. The assumption underlying our research and clearly explicated elsewhere (Coleman, 2014; Valdesolo et al., 2017; Gottlieb et al., 2018; McPhetres, 2019) is that awe promotes engagement and learning. However, giving careful consideration of the "chills" indicators raises the possibility that the awe-engagement association may depend on the interaction of facet and timescale. Although liberation/connection might serve to motivate outward attention in the moment (because of the sense of connection), for example, chills might not have this motivational impetus. If chills are experienced as pleasurable - particularly likely here, in that the awe elicitors combined physical vastness with beauty - then individuals might be motivated to "stay 
in the moment," avoiding careful thought to maintain their ongoing affective state. They also may relate chills to their physical presence, thus focusing attention to their body and personal space. Thus, chills might function to imbue the eliciting information with positivity, promoting future interest in learning, but might not engage critical thought in the moment. This is an intriguing possibility that remains to be tested.

\section{General Discussion}

Museums and other cultural institutions are often in the business of awe. They design their spaces and programming to inspire awe, often to the point of taking it for granted. In this study, we measured awe in museum spaces to first test a priori assumptions that guests are indeed feeling awe. Then we explored whether awe and its correlates were related to museum guests' epistemological relationships with the space and exhibit content and whether awe could be used to encourage engagement and learning.

Across two studies, we explored the experience of awe within a science museum setting, and its relation to learning-related engagement. With regard to the awe experience itself, we observed striking consistency across the studies: Relative to baseline spaces, vast, beautiful spaces (the rotunda and main hall) elicited positive awe-related emotions such as amazement and curiosity, and stronger awe correlates in the form of stronger chills and diminished-self perceptions. For their part, vast, spaces associated with more serious content (the U-505 exhibit) also elicited amazement, stronger chills, and diminished-self perceptions - but also stronger feelings of oppression and isolation. This could be a result of that particular exhibit being designed to educate the guest on what life was like on a German World War Two era submarine - which was both oppressive (living conditions) and isolating (alone in the ocean for months at a time). 
What makes these findings noteworthy? Aside from being able to demonstrate that museum guests self-report differences in awe across settings in a theory-consistent way, they also pave the way for exploring the impact of awe on learning-related engagement, or at least indicators that suggest a positive orientation toward learning. Here, we also observed consistency across studies: Examining the associations between awe and pre-visit knowledge about locationrelevant topics, we observed that those participants who reported greater pre-visit knowledge also reported a stronger sense of liberation/connection and stronger chills in both studies. In terms of pre-visit enjoyment of learning about location-relevant topics, we observed that those participants who reported greater pre-visit learning enjoyment also reported not only a stronger sense of liberation/connection but also more amazement in both studies; in Study 1, these participants also reported stronger chills. Much of the support for awe as a learning tool is based on awe being associated with surprise (Valdesolo et al. 2017). Our findings suggest that appreciation was a stronger driver of awe than surprise.

We were also able to examine engagement and visual thinking as an outcome of awe. In Study 2, subsets of participants completed measures of either visual thinking (associated with more critical observation and communication skills) or skepticism (associated with more careful, systematic use of evidence). We found that stronger diminished-self perceptions and chills were associated with improvements in specific facets of visual thinking, but that stronger feelings of oppression/isolation were associated with lower overall visual thinking scores. These results provide some support for previous assertions that awe is a catalyst for learning (Valdesolo et al. 2017; Gottlieb et al., 2018; McPhetres, 2019), but also add a caveat, in that negative awe might act as an inhibitor. Given other suggestions that negative emotions can be used as a catalyst to 
stir interest (Sinatra, et al, 2015), one implication could be to use negative awe at the start of a learning process and then transition to positive aspects of awe after interest is sustained.

Our results regarding skepticism similarly suggest that the proposed link between awe and engagement and critical thinking is more complex than the "awe as a positive catalyst" argument suggests. Although we found that positive aspects of awe (feelings of liberation/connection, curiosity) were associated with more skepticism, we also found that negative aspects of awe (feelings of oppression/isolation, disorientation) were associated with less skepticism. We also found that stronger chills were associated with less skepticism. This latter result was surprising, given our assumption that chills would be experienced as pleasurable in the context of beautiful architecture (an assumption supported by above-midpoint mean scores of positive awe and below-midpoint mean scores for negative awe). The relationship between chills and other facets of awe, and the role of chills in engagement and learning remain to be discerned.

The skepticism results are in line with Griskevicius et al.'s (2010) findings that awe was related to improved ability to reject weak evidence in argumentation, which is a logical result of more skeptical thinking. It is also somewhat in line with Gottlieb et al.'s (2018) findings that "general positivity tends to run counter to awe" (p. 11). However, our results are in contrast to Valdesolo and Graham's (2014) findings that awe causes people to downplay uncertainty and become more open to "supernatural" beliefs. Their study stimulated awe through the use of nature videos on computer and video screens. We posit that the learning/new experience aspect of awe is not as salient in memory-based awe experiences as in experiential awe simply due to its inherent association with an experience they already had. Our results also differ from Darbor et al. (2016), who found that people experiencing awe tended to reduce or downplay uncertainty. In 
our case, there was a positive relationship between awe and skepticism. Ultimately, Darbor, et al. suggests these differences could depend on how one defines the construct of awe. This is where our more ecologically valid measurement of awe (experiential awe) is important as it measures the levels of awe that people are experiencing in a real world situation using a wide variety of cues. Therefore, one could interpret our measured construct of awe as being very broad, yet importantly, our construct reflects how people feel and report awe in authentic situations. Why would that be associated with skepticism? Perhaps because experiential awe creates a smaller sense of self and a greater awareness of what one does not yet know. Awe induced in nonauthentic settings could be missing some of the elements associated with experiential awe since it is not truly new (e.g., it is common to have seen imagery of the Grand Canyon, but it is less common to have actually visited it). Further research using multifaceted instruments like the SAS (Author et al., under revision) in laboratory settings may shed more light on this difference. Importantly, our study shows that it is no longer appropriate to assume that states of awe are equivalent in all people in all settings.

\section{Awe and Museum Spaces: Implications for Learning}

Awe in particular is a profound and complex amalgam of many other emotions. Perhaps this complexity lends itself to awe being one of the most powerful emotional experiences in a person's life. Embedding ideas, concepts, and experiences in awe-related emotions may open the mind to new ideas. However, it is not easily elicited in formal education environments that are often constrained by financial and operational restrictions. Also, students tend to spend a very large amount of time in those spaces (e.g., multiple hours per day in the same classroom for nine months). As the novelty wears off, so can awe, even in the most inspiring of spaces. A visit to a 
museum provides an opportunity to inspire awe for all types of learners, including guests, visiting school groups, and educators attending professional development training and more.

The implications of these results cross the formal-informal education divide. For example, educators leading school field trips may want to have post-visit discussions with the class as soon as possible after the end of their visit, before the awe wears off. Perhaps this can take place while waiting for the bus in a loading area or riding buses back to the classroom. During that time, they can focus on the more complex topics they encountered in their visit, while other aspects of their visit (e.g., affective responses) could be explored later in the classroom. Exhibit designers could think about how to inspire awe in ways that do not require grand, resource-intensive spaces. This could be especially useful to designers working for institutions that have more limited physical and financial resources.

The limits of experiential awe should also be considered. We have found evidence of negative impacts of oppressive aspects of awe on learning. Maybe a complex message, or one that takes time to consider, should not be introduced while the guest is immersed in a heavy state of awe. Along the same lines, our findings provide support for making spaces of reflection available in areas that create awe, allowing guests to digest what is going on in their mind, as has been suggested by other exhibit designers (McIntyre, 2009; Skydsgaard, Møller Andersen, \& King, 2016). Researchers should consider studying awe in more ecologically valid, real world environments (Anderson, 2016). Like us, others have also shown differences in results from studies done in laboratories vs. museums (Makin, 2017; Pelowski, Forster, Tinio, Scholl \& Leder, 2017; Silvia, 2017). Finally, much of the research on emotions in exhibits has shown a greater impact on delayed measures, and recent work on positive impacts of awe on issues such as social well-being and stress has lasted as long as one week after the awe inducing event 
(Anderson, 2016). These combined with our current set of findings suggest that the next logical future direction would be to conduct research on the long term cognitive impacts of awe.

\section{Limitations}

One clear limitation of these studies is their reliance on subject self-selection. Science museum guests do not reflect demographics of society at large (Feinstein \& Meshoulam, 2014; DeWitt \& Archer, 2017). Certainly, it would be important to test the replicability of our findings with a different form of sampling. In terms of our focus on awe, however, we believe our results cannot be attributed solely to the characteristics of our sample. Our participants did not selfreport as particularly awe-prone, with mean scores on the dispositional awe measure (Study 1) being $1.47(\mathrm{SD}=0.92)$ on a -3 to +3 scale, suggesting that they would be relatively unlikely to differ dramatically in how much awe they experienced during their museum visit. With our focus on investigating the impact of awe on learning-related variables, our ability to reliably evoke different levels of awe across our target locations supports our ability to study its impact in this setting, and our sample's moderate levels of self-reported awe proneness supports our belief that our results would replicate with a different sampling plan.

It should also be noted that we took a broad approach to measuring critical thinking by using a technique, VTS, that involves the presence and use of evidence in our guests' aesthetic thinking. Prior research has shown VTS to be a sensitive measure of critical thinking in both museums and science education settings (Adams, Foutz, Luke, \& Stein, 2006; DeSantis \& Housen, 2007; Kisida, Bowen, \& Greene, 2016; Curtin \& McConnell, 2017; Moorman, Hensel, Decker \& Busby, 2017). However, critical thinking is a broad construct (Liu, Frankel, \& Roohr, 2014) and there are likely other components of critical thinking that may be impacted by experiential awe that could be explored using next generation critical thinking assessments (Liu, 
Mao, Frankel, \& Xu, 2016). In addition, the skepticism scale that we used was designed to measure trait skepticism (Hurtt, 2010), but we used it here to measure state skepticism. The current results demonstrate that the PSS is sensitive to situational changes, but its unvalidated status as a state measure means caution should be taken in interpreting these results.

\section{Conclusion}

Recent studies have suggested that awe can sharpen the brain (Shiota, 2016). Most of those studies have taken place in laboratory settings and involve awe induced by memory or association. A goal of educational psychology is to address how people learn in real world situations (Woolf, Woolf, Lane, Chaudhri \& Kolodner, 2013). Museums are emotional places (May, Schlictmann, Paneto \& Ducharme, 2018) with both experiential and learning goals. As such, they are in a unique position to test and determine whether there are connections between awe and learning. The studies reported in this paper examined the experience of awe in a science museum, and how that experience related to engagement in the form of skepticism and critical thinking - and demonstrated that various facets of awe correlate with aspects of these engagement indicators. However, these correlations were not all positive, underscoring the importance of considering awe as a multi-faceted construct. Additional research will be required to provide educators and museum program curators with the knowledge necessary to promote awe in a way that helps them achieve their education goals. 


\section{References}

Adams, M., Foutz, S., Luke, J., \& Stein, J. (2006). Thinking through art: Isabella Stewart Garner museum school partnership program year 3 preliminary research results. Edgewater, MD: Institute for Learning Innovation.

Anderson, C. C. (2019). The art of medicine: A narrative case study of an art museum workshop series for first-year medical students (Doctoral dissertation).

Awe. (n.d.). In Oxford English Dictionary [online]. Retrieved from https://en.oxforddictionaries.com/definition/awe

Ballantyne, R., Packer, J., Hughes, K., \& Dierking, L. (2007). Conservation learning in wildlife tourism settings: Lessons from research in zoos and aquariums. Environmental Education Research, 13, 367-383.

Caranfa, A. (2003). Philosophical silence and spiritual awe. The Journal of Aesthetic Education, 37, 99-113.

Coleman, T.C. (2014). Positive emotion in nature as a precursor to learning. International Journal of Education in Mathematics, Science and Technology, 2, 175-190.

Curtin, S. \& McConnell, M. (2017). Introducing critical thinking to dental undergraduates. Retrieved from https://www.ucc.ie/en/media/academic/visualthinkingstrategies/IntroducingCriticalThinki ngtoDentalUndergraduates.pdf

Danvers, A. F., \& Shiota, M. N. (2017). Going off script: Effects of awe on memory for scripttypical and-irrelevant narrative detail. Emotion, 17, 938-952. 
Darbor, K. E., Lench, H. C., Davis, W. E., \& Hicks, J. A. (2015). Experiencing versus contemplating: Language use during descriptions of awe and wonder. Cognition and Emotion, 30, 1188-1196.

DeSantis, K. \& Housen, A. C. (2000). A brief guide to developmental theory and aesthetic development. Visual Understanding in Education.

DeSantis, K. \& Housen, A. (2007). Aesthetic development and creative and critical thinking skills study. Visual Thinking Strategies.

DeWitt, J., \& Archer, L. (2017). Participation in informal science learning experiences: The rich get richer? International Journal of Science Education, Part B, 7, 356-373.

Ecklund, E. H., \& Long, E. (2011). Scientists and spirituality. Sociology of Religion, 72, 253274.

Falk, J. H., \& Dierking, L. D. (2010). The 95 percent solution. American Scientist, 98(6), 486493.

Falk, J. H., \& Gillespie, K. L. (2009). Investigating the role of emotion in science center visitor learning. Visitor Studies, 12, 112-132.

Feinstein, N. W., \& Meshoulam, D. (2014). Science for what public? Addressing equity in American science museums and science centers. Journal of Research in Science Teaching, 51, 368-394.

Foss, S. (2014). Visual, critical, and scientific thinking dispositions in a 3rd grade science classroom (Doctoral dissertation, Walden University, Minneapolis, MN).

Girod, M. (2007). A conceptual overview of the role of beauty and aesthetics in science and science education, Studies of Science Education, 43, 38-61. 
Gordon, A. M., Stellar, J. E., Anderson, C. L., McNeil, G. D., Loew, D., \& Keltner, D. (2017). The dark side of the sublime: Distinguishing a threat-based variant of awe. Journal of Personality and Social Psychology, 113, 310-328.

Gottlieb, A., Keltner, D. \& Lombrozo, T. (2018). Awe as a scientific emotion. Cognitive Science, 42, 2081-2094.

Greene, J., Kisida, B., \& Bowen, D. H. (2014). The educational value of field trips. Education Next, 14.

Griskevicius, V., Shiota, M. N., \& Neufeld, S. L. (2010). Influence of different positive emotions on persuasion processing: A functional evolutionary approach. Emotion, 10, 190-206.

Hascher, T. (2010). Learning and emotion: perspectives for theory and research. European Educational Research Journal, 9, 13-28.

Housen, A., (2002). Aesthetic thought, critical thinking and transfer. Arts and Learning Research Journal, 18, 99-131.

Housen, A. (2007). Art viewing and aesthetic development: Design for the viewer. Visual Understanding in Education.

Hubard, O. (2011). Rethinking critical thinking and its role in art museum education. Journal of Aesthetic Education, 45, 15-21.

Hurtt, R. K. (2010). Development of a scale to measure professional skepticism. Auditing: A Journal of Practice \& Theory, 29, 149-171.

Jaber, L. Z., \& Hammer, D. (2016). Engaging in science: A feeling for the discipline. Journal of the Learning Sciences, 25, 156-202.

Jaber, L. Z., \& Hammer, D. (2016). Learning to feel like a scientist. Science Education, 100, 189-220. 
Keltner, D., \& Haidt, J. (2003). Approaching awe, a moral, spiritual, and aesthetic emotion. Cognition \& Emotion, 17, 297-314.

King, D., Ritchie, S., Sandhu, M., \& Henderson, S. (2015). Emotionally intense science activities. International Journal of Science Education, 37, 1886-1914.

Kisida, B., Bowen, D. H., \& Greene, J. P. (2016). Measuring critical thinking: Results from an art museum field trip experiment. Journal of Research on Educational Effectiveness, $9(\sup 1), 171-187$.

Klugman, C.M., \& Beckmann-Mendez, D. (2015). One Thousand Words: Evaluation an Interdisciplinary Art Education Program. Journal of Nursing Education, 54, 220.

Kokkos, A. (2013). The use of aesthetic experience in unearthing critical thinking. In X. Y. Zee (Ed.), Learning with adults (pp. 205-217). Rotterdam, Netherlands: SensePublishers.

Krenzer, W. L. D., Greenslit, J., Price, C. A., Krogh-Jespersen, S., \& Quinn, K. Q. (under revision). Assessing the experience of awe: Validating the Situational Awe Scale.

Lai, E. R. (2011). Critical thinking: A literature review. Pearson's Research Reports, 6, 40-41. Lankford, E. L. (2002). Aesthetic experience in constructivist museums. Journal of Aesthetic Education, 36, 140-153.

Linnenbrink-Garcia, L., \& Pekrun, R. (2011). Students' emotions and academic engagement: Introduction to the special issue. Contemporary Educational Psychology, 36, 1-3.

Liu, O. L., Frankel, L. \& Roohr, K. C. (2014). Assessing critical thinking in higher education: current state and directions for next-generation assessment (Report No. RR-14-10). Princeton, NJ: Education Testing Service. 
Liu, O. L., Mao, L., Frankel, L., \& Xu, J. (2016). Assessing critical thinking in higher education: the HEIghten ${ }^{\mathrm{TM}}$ approach and preliminary validity evidence. Assessment \& Evaluation in Higher Education, 41, 677-694.

Lombardi, D., \& Sinatra, G. M. (2012). College students' perceptions about the plausibility of human-induced climate change. Research in Science Education, 42, 201-217.

Lorini, E., \& Castelfranchi, C. (2007). The cognitive structure of surprise: Looking for basic principles. Topoi, 26, 133-149.

Mahn, H., \& John-Steiner, V. (2002). The gift of confidence: A Vygotskian view of emotions. Learning for life in the 21st century, 46-58.

Makin, A. D. (2017). The gap between aesthetic science and aesthetic experience. Journal of Consciousness Studies, 24(1-2), 184-213.

McIntyre, C. (2009). Museum and art gallery experience space characteristics: an entertaining show or a contemplative bathe?. International Journal of Tourism Research, 11, 155170.

Moorman, M., Hensel, D., Decker, K. A., \& Busby, K. (2017). Learning outcomes with visual thinking strategies in nursing education.

Pelowski, M., Forster, M., Tinio, P. P., Scholl, M., \& Leder, H. (2017). Beyond the lab: An examination of key factors influencing interaction with 'real' and museum-based art. Psychology of Aesthetics, Creativity, and the Arts, 11, 245.

Piff, P. K., Dietze, P., Feinberg, M., Stancato, D. M., \& Keltner, D. (2015). Awe, the small self, and prosocial behavior. Journal of Personality and Social Psychology, 108, 883-899.

Pintrich, P. R. (2003). A motivational science perspective on the role of student motivation in learning and teaching contexts. Journal of Educational Psychology, 95, 667. 
Price, C. A., Lee, H.-S., SubbaRao, M., Aguilera, J. \& Kasal, E. (2015). Comparing short and long-term term learning effects between stereoscopic and two-dimensional film at a planetarium. Science Education, 99.

Rappolt-Schlictmann, G., Evans, M., Reich, C. \& Cahill, C. (2017, Spring). Core emotion and engagement in informal science learning. Exhibition, 43-50.

Reilly, J. M., Ring, J., \& Duke, L. (2005). Visual thinking strategies: A new role for art in medical education. Family Medicine, 37, 250-252.

Rienties, B., \& Rivers, B. A. (2014). Measuring and understanding learner emotions: Evidence and prospects. Learning Analytics Review, 1, 1-28.

Roth, W. M., \& Lee, Y. J. (2007). "Vygotsky’s neglected legacy”: Cultural-historical activity theory. Review of educational research, 77, 186-232.

Sagan, C. (1995). Wonder and skepticism. Skeptical Inquirer, 19(1). Retrieved from https://www.csicop.org/si/show/wonder_and_skepticism

Sakr, M., Jewitt, C., \& Price, S. (2016). Mobile experiences of historical place: A multimodal analysis of emotional engagement. Journal of the Learning Sciences, 25, 51-92.

Shiota, M. N., Keltner, D., \& John, O. P. (2006). Positive emotion dispositions differentially associated with Big Five personality and attachment style. The Journal of Positive Psychology, 1, 61-71.

Shiota, M. N., Keltner, D., \& Mossman, A. (2007). The nature of awe: Elicitors, appraisals, and effects on self-concept. Cognition \& Emotion, 21, 944-963.

Shiota, M., Thrash, T. M., Danvers, A. F., \& Dombrowski, J. T. (2014). Transcending the Self: Awe, elevation, and inspiration. In M. M. Tugade, M. N. Shiota, \& L. D. Kirby (Eds.), Handbook of positive emotions (pp. 362-337). New York, NY: Guilford Press. 
Silvia, P. J. (2008). Interest-The curious emotion. Current Directions in Psychological Science, $17,57-60$.

Silvia, P. J. (2017). Aesthetics, creativity, and the arts in everyday environments. Psychology of Aesthetics, Creativity, and the Arts, 11, 243-244.

Simpson, J., \& Weiner, E. S. (1989). Oxford English dictionary online. Oxford: Clarendon Press. Retrieved from https://www.oxfordlearnersdictionaries.com/us/definition/english/awe_1

Sinatra, G. M., Broughton, S. H., \& Lombardi, D. (2014). Emotions in science education. International handbook of emotions in education, 415-436.

Sinatra, G. M., Heddy, B. C., \& Lombardi, D. (2015). The challenges of defining and measuring student engagement in science. Educational Psychologist, 50, 1-13.

Skydsgaard, M. A., Møller Andersen, H., \& King, H. (2016). Designing museum exhibits that facilitate visitor reflection and discussion. Museum Management and Curatorship, 31, $48-68$.

Smith, J. K. (2014). The museum effect: How museums, libraries, and cultural institutions educate and civilize society. New York, NY: Rowman \& Littlefield.

Smith, L. F., \& Smith, J. K. (2006). The nature and growth of aesthetic fluency. In P. Locher, C. Martindale, \& L. Dorfman (Eds.), Foundations and Frontiers in Aesthetics. New directions in aesthetics, creativity and the arts (pp. 47-58). Amityville, NY: Baywood Publishing Co.

Stahl, A. E., \& Feigenson, L. (2015). Observing the unexpected enhances infants' learning and exploration. Science, 348(6230), 91-94. 
Treagust, D. F., \& Duit, R. (2008). Conceptual change: A discussion of theoretical, methodological and practical challenges for science education. Cultural Studies of Science Education, 3, 297-328.

Trevors, G. J., Muis, K. R., Pekrun, R., Sinatra, G. M., \& Winne, P. H. (2016). Identity and epistemic emotions during knowledge revision: A potential account for the backfire effect. Discourse Processes, 53(5-6), 339-370.

Valdesolo, P., \& Graham, J. (2014). Awe, uncertainty, and agency detection. Psychological Science, 25, 170-178.

Valdesolo, P., Park, J., \& Gottlieb, S. (2016). Awe and scientific explanation. Emotion, 16, 937940.

Valdesolo, P., Shtulman, A., \& Baron, A. S. (2017). Science is awe-some: The emotional antecedents of science learning. Emotion Review, 9, 215-221.

Vygotsky, L. S. (1926). Esthetic education (Silverman, R., Trans.). In Educational psychology (pp. 241-268). FL: CRC Press.

Vygotsky, L. S. (1997). Educational Psychology. FL: CRC Press.

Wellbery, C., \& McAteer, R. A. (2015). The art of observation: A pedagogical framework. Academic Medicine, 90(, 1624-1630.

Woolf, B. P., Lane, H. C., Chaudhri, V. K., \& Kolodner, J. L. (2013). AI grand challenges for education. AI magazine, 34, 66-85.

Yenawine, P. (2013). Visual thinking strategies: Using art to deepen learning across school disciplines. Cambridge, MA: Harvard Education Press. 
Zembylas, M. (2005). Three perspectives on linking the cognitive and the emotional in science learning: Conceptual change, socio-constructivism and poststructuralism. Studies in Science Education, 41, 91-116. 
Table S1

Hierarchical Linear Models for Composite Visual Thinking Strategy Use and Individual Visual Thinking Strategy Use Predicted by Item and Momentary Awe Subscale Score, Study 2

\begin{tabular}{|c|c|c|c|}
\hline Fixed Effects & Estimate & Std. Error & $p$ \\
\hline \multicolumn{4}{|l|}{ Composite } \\
\hline (Intercept) & -1.62 & 0.10 & $<.001$ \\
\hline Q: Camping & -0.12 & 0.07 & .099 \\
\hline Q: Jet & -0.19 & 0.08 & .01 \\
\hline Liberation/connection & -0.05 & 0.05 & .36 \\
\hline Oppression/isolation & -.10 & 0.04 & .01 \\
\hline Chills & -.03 & 0.04 & .44 \\
\hline Diminished self & 0.06 & 0.04 & .12 \\
\hline \multicolumn{4}{|l|}{ Observation } \\
\hline (Intercept) & -0.56 & 0.34 & .10 \\
\hline Q: Camping & 0.38 & 0.28 & .18 \\
\hline Q: Jet & 0.04 & 0.28 & .88 \\
\hline Liberation/connection & -0.09 & 0.16 & .55 \\
\hline Oppression/isolation & -0.09 & 0.12 & .45 \\
\hline Chills & -0.03 & 0.13 & .81 \\
\hline Diminished self & 0.37 & 0.14 & .008 \\
\hline \multicolumn{4}{|l|}{ Interpret object } \\
\hline (Intercept) & -2.38 & 0.25 & $<.001$ \\
\hline Q: Camping & 0.78 & 0.20 & $<.001$ \\
\hline Q: Jet & 0.28 & 0.22 & .21 \\
\hline Liberation/connection & -0.01 & 0.10 & .95 \\
\hline Oppression/isolation & -0.14 & 0.08 & .09 \\
\hline Chills & -0.12 & 0.08 & .13 \\
\hline Diminished self & 0.09 & 0.08 & .26 \\
\hline \multicolumn{4}{|l|}{ Interpret condition } \\
\hline (Intercept) & -1.29 & 0.28 & $<.001$ \\
\hline Q: Camping & -0.89 & 0.21 & $<.001$ \\
\hline Q: Jet & -1.61 & 0.26 & $<.001$ \\
\hline Liberation/connection & -0.04 & 0.13 & .78 \\
\hline Oppression/isolation & -0.17 & 0.10 & .11 \\
\hline Chills & 0.16 & 0.10 & .13 \\
\hline Diminished self & -0.10 & 0.11 & .34 \\
\hline \multicolumn{4}{|l|}{ Interpret identity } \\
\hline (Intercept) & -0.52 & 0.20 & .0099 \\
\hline Q: Camping & -1.82 & 0.21 & $<.001$ \\
\hline Q: Jet & -0.07 & 0.16 & .66 \\
\hline Liberation/connection & -0.16 & 0.10 & .096 \\
\hline Oppression/isolation & -0.13 & 0.07 & .09 \\
\hline Chills & -0.06 & 0.08 & .43 \\
\hline Diminished self & 0.06 & 0.08 & .47 \\
\hline $\begin{array}{l}\text { Interpret intention } \\
\text { (Intercept) }\end{array}$ & -1.00 & 0.23 & $<.001$ \\
\hline
\end{tabular}




\begin{tabular}{|c|c|c|c|}
\hline Q: Camping & 0.11 & 0.17 & .52 \\
\hline Q: Jet & -0.23 & 0.18 & .20 \\
\hline Liberation/connection & -0.09 & 0.11 & .43 \\
\hline Oppression/isolation & -0.11 & 0.08 & .19 \\
\hline Chills & -0.08 & 0.09 & .37 \\
\hline Diminished self & 0.19 & 0.09 & .04 \\
\hline \multicolumn{4}{|l|}{ Evaluate } \\
\hline (Intercept) & -4.81 & 0.69 & $<.001$ \\
\hline Q: Camping & 1.45 & 0.48 & .003 \\
\hline Q: Jet & 0.62 & 0.54 & .25 \\
\hline Liberation/connection & 0.03 & 0.24 & .91 \\
\hline Chills & 0.38 & 0.18 & .03 \\
\hline Oppression/isolation & -0.31 & 0.19 & .11 \\
\hline Diminished self & -0.16 & 0.19 & .38 \\
\hline \multicolumn{4}{|l|}{ Compare* } \\
\hline (Intercept) & -4.29 & 0.58 & $<.001$ \\
\hline Q: Camping & 1.13 & 0.34 & $<.001$ \\
\hline Liberation/connection & -0.08 & 0.20 & .69 \\
\hline Oppression/isolation & -0.25 & 0.18 & .16 \\
\hline Chills & -0.30 & 0.16 & .07 \\
\hline Diminished self & 0.03 & 0.17 & .87 \\
\hline \multicolumn{4}{|l|}{ Flexible thinking } \\
\hline (Intercept) & -3.00 & 0.39 & $<.001$ \\
\hline Q: Camping & 0.13 & 0.26 & .62 \\
\hline Q: Jet & 0.14 & 0.27 & .60 \\
\hline Liberation/connection & 0.19 & 0.17 & .26 \\
\hline Oppression/isolation & -0.07 & 0.13 & .60 \\
\hline Chills & -0.12 & 0.13 & .36 \\
\hline Diminished self & 0.02 & 0.14 & .88 \\
\hline
\end{tabular}

Note. Significant momentary awe (liberation/connection, oppression/isolation, chills, diminished self) predictors are highlighted in bolded text. *The Jet question was removed from the analysis because there were no responses that indicated comparison thinking. 